\title{
DIHAR SITARLAK PADA MASYARAKAT SIMALUNGUN : KAJIAN SEMIOTIK
}

\author{
Sari Mega Florensia Simanungkalit ${ }^{1}$, Nurwani $^{2}$, Iskandar Muda ${ }^{3}$ \\ Prodi Pendidikan Tari/ Fakultas Bahasa dan Seni/ Universitas Negeri Medan \\ Jalan Willem Iskandar Pasar V Medan Estate 20221, Sumatera Utara-Indonesia \\ ${ }^{1}$ SarimegaflorensiaS@gmail.com, 르wrwanipilago@gmail.com, ${ }^{3}$ iskandarmuda_msn@yahoo.com
}

\begin{abstract}
This study examines the semiotics contained in diharsitarlak in Simalungun society. The goal is to explore the meaning contained in the sararar and interpretation of meaning seen through the theory of semiotics. Sitarlak is a martial arts that comes from Simalungun who became the performing arts for the community that is as a welcome dance for accompanied by music and using a special outfit. The theory used relates to the research topic of Suzanna $K$. Langer theory which discusses the motion and the theory of semiotic de Saurrsure to express the meaning. The research time used to discuss the semiotics was held in Simalungun society was done for 2 months ie end of August until October 2017. The research place was SanggarTortor Elak-elak in Kelurahan Sirpang Dalig Raya, Raya Subdistrict, Simalungun Regency. Population in this research is artist as well as adat character, sambual (pemusik), pandihar (people who bersilat) who understand about diharsitarlak. Data collection techniques include literature study, observation, interview and documentation, and then analysis with qualitative descriptive method. Based on the research conducted, the form of diharsitarlak is a series of silat movements consisting of 7 main motifs yaitu sombah, throw boxing worship, marsimbur, mangindo (top level), mangindo (lower level), lakkasitolu-tolu and cover worship. Clothing that is used in the sitarlakdihar is long shirt and trousers (black, red, and mixture of black, white, red), yeast pane, suri-suri, and gotong salalu. The accompaniment of music on the sitarlakdihar gondrang haro-day, parahot, and gual porang. As for the semiotics contained in the scarred sitarlak poured through the sign (sign) seen from the form of motion in the series of presentation, marker (signifier) is a form of motion as the main motive in the diharsitarlak, and signified (signified) is the meaning contained in diharsitarlak. So it can be interpreted the overall meaning in the absolute sarar is the actualization of life of the people of Simalungun in various conditions, such as giving thanks to God, facing temptation, being polite and humble, respecting and appreciating others.
\end{abstract}

Keywords: semiotics, signs, signifer, signified, diharsitarlak

\section{PENDAHULUAN}

Dihar (silat) atau mandihar (bersilat) merupakan seni bela diri yang berasal dari daerah Simalungun. Dihar memiliki sikap dasar gerakan yang tidak arogan atau tidak menunjukkan kesombongan dan juga menggambarkan bahwa masyarakat Simalungun mempunyai pertahanan diri yang kuat. Selain untuk pertahanan diri, mandihar biasanya dilakukan masyarakat Simalungun dalam suatu prosesi adat maupun kegiatan resmi untuk menyambut tamu-tamu kehormatan seperti Raja Simalungun..

Menurut narasumber Dihar terbagi atas beberapa, yaitu Dihar Horbou Sihalung, Dihar Sitarlak, Dihar Rimau Putih, Dihar Balang Sahua, Dihar Bona
Uhur, Dihar Natar. Dari beberapa dihar tersebut, dihar sitarlak dijadikan rujukan dalam penelitian ini. Dihar sitarlakini biasanya dilakukan oleh dua orang atau kelompok namun tetap berpasangan. Dihar sitarlak dilakukan dalam acara adat Simalungun yang digunakan untuk menyambut tamu kehormatan yang ada di Simalungun. Alat musik yang digunakan pada dihar sitarlak yaitu gondrang sidua-dua, sarunei, gong atau ogung dan mongmongan. Gondrang yang sering digunakan untuk mengiringi dihar ini adalah haro-haro, parahot, dan gual porang. Adapun busana yang digunakan pada dihar ini ada tiga jenis yaitu 1)busana hitam yang terdiri dari baju berwarna hitam, celana hitam, ragi pane, suri-suri dan gotong, 2) busana merah 
yang terdiri dari baju berwarna merah, celana merah, ragi pane, suri-suri dan gotong, 3) polang-polang (busana berwarna campran hitam, merah, putih), ragi pane, suri-suri dan gotong.

Dalam tari ini ada yang harus dipahami dan dimengerti oleh penikmat lewat tanda-tanda atau simbol-simbol yang dikomunikasikan melaui simbol gerak atau simbol lain sebagai pendukungnya maka, penulis mencoba untuk meneliti lebih dalam dengan mengkajinya melalui teori semiotik, dimana peneliti akan mengkaji tanda, penanda, dan petanda dalam gerakan diharsitarlak sebagai kajian semiotikanya. Maka dari itu penulis mengangkat tarian ini menjadi topik penelitian dengan judul.

\section{METODOLOGI.}

"DiharSitarlak Pada Masyarakat

Simalungun : kajian semiotik".

\section{Lokasi dan Waktu Penelitian}

Lokasi penelitian ini dilaksanakan di Sanggar Tortor elak-elak di Kecamatan Raya, Kabupaten Simalungun. Alasan pemilihan tempat ini karena di sanggar ini terdapat seniman Simalungun yaitu Bapak Sahat Damanik, tokoh adat Simalungun, masyarakatmasyarakat setempat yang mengetahui tentang diharsitarlak. Penelitian diharsitarlak pada masyarakat Simalungun dilakukan selama tiga bulan yaitu bulan Agustus sampai November 2017.

\section{Populasi dan Sampel}

Populasi yang akan diteliti dalam penelitian ini adalah 2 orang seniman yang sekaligus menjadi tokoh adat, 2 orang pandihar (orang yang bersilat), 7 orang panggual (pemusik) yang mengetahui dan mengerti Dihar sitarlak di Kabupaten Simalungun. Penelitian ini dapat disebut dengan penelitian populasi karena sampel dalam penelitian ini adalah keseluruhan dari populasi.

\section{Teknik Analisis Data}

Dalam penelitian ini penulis mengumpulkan seluruh informasi dan data-data dari kepustakaan, wawancara, observasi dan dokumentasi dikumpulkan, maka penulis menganalisa dan menguraikan data-data tersebut dengan menggunakan teknik deskriptif kualitatif sebagai prosedur pemecahan masalah yang diselidiki dengan menggambarkan keadaan objek penelitian pada saat sekarang.

\section{PEMBAHASAN.}

\section{A.Masyarakat Simalungun}

Suku Batak Simalungun memiliki marga yang menunjukkan identitas dari keturunan mana mereka berasal. Dalam bahasa Simalungun marga disebut morga. Nama marga ini diperoleh dari garis keturunan ayah yang selanjutnya akan diteruskan laki-laki secara terus menerus. Masyarakat Simalungun juga memiliki sistem kekerabatan. Sistem kekerabatan yang dimiliki masyarakat Simalungun adalah berdasarkan prinsip tolu sahundulan yang tediri dari sanina (saudara semarga), tondong (pihak keluarga istri), anak boru (pihak penerima istri atau pihak yang mengambil istri dari suatu marga). Disamping itu terdapat lagi pihak-pihak yang disebut : 1) Tondong $n i$ tondong, yaitu pihak keluarga nenek (saudara lakilakinya mertua perempuan atau tulangnya istri) 2) Boru ni boru atau borumitori, yaitu pihak anak gadis dari pengambil anak gadis (iparnya ipar). Dengan demikian lima pihak dalam struktur masyarakat yang kelimalimanya yang disebut dengan istilah "lima saodoran".

\section{B. Dihar Sitarlak}

\section{Keberadaan Diharsitarlak}


Diharsitarlak berasal dari daerah Simalungun yang merupakan salah satu seni bela diri masyarakat Simalungun. Menurut beberapa seniman dan tokoh adat Simalungun yang menjadi narasumber dalam penelitian menjelaskan sejarah diharsitarlak. Dahulunya sitarlak dinamakan sitaraleak namun setelah tahun 1990an sering disebut sitarlak. Dihar pada dulunya hanya dilakukan oleh dua sosok yang disebut raja Simalungun dan datu.

Dihar sitarlak memiliki bentuk gerak yang terdiri dari rangkaian gerak -gerak silat. Dihar ini diawali dan diakhiri dengan gerak sembah yang disebut dengan sombah yang menandakan bahwa masyarakat Simalungun selalu mengucap syukur kepada Tuhan, menghormati dan menghargai sesama. Bentuk gerak dihar sitarlak ada 7 bentuk yang merupakan motif utama diantaranya sombah, buang tinju, marsimbur, mangindo (level atas), mangindo (level bawah), lakka sitolu-tolu dan sombah penutup. Bentuk gerak ini dapat dilakukan berulang kecuali sombah yang dapat dilakukan saat mengawali dan mengakhiri, lakka sitolutolu merupakan langkah pertahanan yang merupakan bunga-bunga dalam silat ini. Bentuk gerak buang tinju, marsimbur dan mangindo dapat dilakukan setelah sembah dan diselingi gerak bunga-bunga yaitu lakka sitolu-tolu (sering disebut gerak transisi). Durasi silat ini tidak ditentukan apabila digunakan untukfightdan untuk penyambutan biasanya berkisar 2 sampai 3 menit.

Selain menjadi pertahanan diri, dihar juga digunakan sebagai ritual menyambut tamu terhormat dalam acara resmi yang ada di Simalungun. Sekarang sudah berkembang bahwa dihar ini sering ditampilkan dalam acara kesenian dan juga digunakan sebagai penyambutan acara-acara yang ada di Simalungun bahkan diacara perkawinan dihar ini juga ditampilkan sebagai penyambutan tanda penghormatan bagi tamutamu yang datang, sehingga dihar ini tidak hanya dikenal sebagai bela diri namun juga merupakan pertunjukan yakni sebuah tortor penyambutan.

\section{Dihar Sitarlak Kajian Semiotika}

Guna mengungkapkan makna yang terdapat dalam diharsitarlak dikaji melalui semiotika Ferdinand de Saurssure, terdiri dari tiga unsur yaitu tanda (sign), penanda (signifier) dan petanda (signified), dimana tanda merupakan kesatuan dari penanda dan petanda yang tidak dapat dipisahkan sehingga memiliki makna. Keseluruhan gerakan diharsitarlak adalah rangkaian gerak-gerak silat yang berfungsi sebagai pertahanan diri dan juga menjadi penyambutan bagi tamu-tamu dalam acara adat Simalungun. Pandihar harus memiliki kejelian badan dalam bergerak karena dalam dihar ini harus memiliki pertahanan badan yang kuat selain menyerang.

Adapun bagian yang dikupas dari diharsitarlak adalah bentuk geraknya. Diharsitarlak memiliki 7 bentuk gerak sebagai motif utama yaitu sombah, buang tinju menyembah, marsimbur, mangindo (level atas), mangindo (level bawah), lakka sitolu-tolu, dan sombah penutup.Dari ketujuh motif tersebut maka dikupas semiotika yang terdapat di dalamnya untuk mendapatkan maknanya.

\section{a. Tanda (Sign)}

Tanda sebagai simbol dalam diharsitarlak dilihat dari bentuk gerak-gerak silat yang terdapat dalam rangkaian bentuk penyajiannya. Tanda yang terdapat dalam dihar sitarlakdilihat dari gerak-gerak silat yang terdapat dalam gerak penyajiannya, yaitu tanda pertama yang dilakukan dengan posisi kaki berdiri tegak, kedua telapak tangan disatukan didepan dada. Tanda kedua dilakukan dengan posisi kaki kuda-kuda membentuk 
diagonal, tangan salah satu pandihar diangkat di depan kepala dengan telapak tangan hampir menyatu, badan tegak dan kepalanya sedikit tunduk. Sedangkan pandihar pasangannya melakukan tanda dengan posisi kaki kuda-kuda, tangan kanan dikepal lurus ke depan seperti meninju dan tangan kiri berada di depan dada, posisi badan dan kepala tegak. Tanda ketiga pandihar membuat posisi kaki kiri kuda-kuda dan kaki kanan diseret dan diangkat ke arah lawan, tangan kanan ke bawah sebatas kaki dan telapak tangannya terbuka, tangan kiri di depan dada dengan badan tegak dan kepala menghadap lawan. Sedangkan pandihar lainnya melakukan tanda dengan posisi kaki kuda-kuda, tangan kanan didepan dada dan tangan kiri diletakkan di atas paha kiri serta kepalanya berpaling dari arah lawan.Tanda keempat dilakukan dengan posisi kaki diagonal kanan dan kuda-kuda, tangan terbuka disisi kanan kiri badan dan telapak tangan kearah atas serta kepala menghadap ke lawan. Tanda kelima dilakukan dengan posisi level bawah, dilakukukan dengan kaki kanan sedikit diagonal kanan dan kaki kiri ditekuk seperti bersimpuh, tangan kanan di atas lutut kanan dengan telapak tangan terbuka keatas sedangkan tangan kiri di depan dada. Tanda keenam dilakukan dengan kaki terbuka, kaki sebelah kanan sedikit ditekuk, tangan kanan diangkat sebatas bahu dan telapak tangan terbuka kedepan, tangan kiri diletakkan di bawah tangan kanan, posisi badan diagonal kanan menikuti arah kaki dan pandangan ke arah lawan. Tanda ketujuh dilakukan dengan kedua telapak tangan disatukan di depan dada.

\section{b. Penanda}

Penanda pada dihar sitarlak merupakan bentuk gerak yang menjadi motif utama yaitu sombah (sembah), buang tinju sembah, marsimbur (membuang pasir ke lawan), mangindo (siap menerima serangan) level atas, mangindo (siap menerima serangan) level bawah, lakka sitolu-tolu (langkah pertahanan) dan sombah (sembah) penutup.

\section{c. Petanda}

Petanda yang terdapat di dalam dihar sitarlak merupakan makna yang terdapat dalam dihar sitarlak yaitu mengucap syukur kepada Tuhan, sabar dan sopan, rendah hati, kegigihan, ketangguhan dan kewaspadaan pada setiap hal dalam kehidupan sehari-hari.

\section{d.Interpretasi makna gerakan dilihat dari tanda, penanda dan petanda}

Dilihat dari ilmu semiotik yang mengandung tanda, penanda dan petanda dapat diinterpretasikan makna keseluruhan dalam dihar sitarlakmerupakan gambaran aktualisasi kehidupan masyarakat Simalungun dalam berbagai kondisi, seperti mengucap syukur kepada Tuhan, menghadapi cobaan, bersikap sopan dan rendah hati, menghormati dan menghargai orang lain.

\section{PENUTUP.}

\section{B. Saran}

Setelah melakukan penelitian dan mendapatkan hasil maka penulis dapat memberikan beberapa saran, yaitu:

1. Agar diharsitarlak trus dikembangkan, diperlukan pemngembangan yang melibatkan berbagai pihak seperti pemerintah, maupun masyarakat sekitar.

2. Kepada generasi muda diharapkan untuk dapat mempelajari lagi lebih dalam mengenai warisan kebudayaan Simalungun secara baik dan benar sesuai norma dan adat istiadat yang berlaku guna pelestarian budaya.

3. Peneliti berharap kepada peneliti selanjutnya agar dapat lebih banyak menggali atau memahami 
mengenai keberadaan budaya etnis Batak Simalungun ini, maupun etnis-etnis lainnya di Indonesia

Dari hasil skripsi ini, menyarankan bagi mahasiswa yang akan melanjutkan tugas akhir skripsi untuk penelitian yang bernuansakan adat istiadat dan budaya suku-suku di Indonesia lainnya agar dapat lebih memahami indahnya ragam budaya yang ada di Indonesia

\section{DAFTAR PUSTAKA}

Arikunto, Suharsimi. 1995. Manajemen Penelitian.Jakarta : Rineka Cipta

Ayu Yaritha, Dian. 2016. Analisis Semiotika Dalam Ragam Gerak Tari Sigeh Pengunten. Universitas Negeri Lampung: Bandar Lampung.

Budiman, Kris. 1999. Kosa Semiotika.LkiS : Bandung.

Danesi, Marcel. 2004. Pesan, Tanda, dan Makna. Jalasutra : Yogyakarta.

De Marinis, Marco. 1993. The Semiotics of Performance. Indiana University Press :America.

Eco, Umberto. 2011. Teori Semiotika. Indiana Univesity Press : America.

Edo Wicaksono, Yahya.2014. Semiotika Tari Cokronegoro Sebagai Tarian Khas Kabupaten Sidoarjo. UNESA: Semarang.

Jalun, Melkias. 2015. Analisis Semiotika Pakaian Adat Dayak Bahau Sebagai Alat Komunikasi Budaya Dalam Berinteraksi Dalam Masyarakat. Universitas Mulawarman.

Kaelan,M.S. 2009. Filsafat Bahasa Semiotika dan Hermeutika.Paradigma : Yogyakarta.

K.Langer, Suzanne. 1988. Problematika Seni Akedemi Seni Tari Indonesia : Bandung.

Murgianto, Sal.1983. Koreografi (Pengetahuan Dasar Komposisi Tari). Dapertemen Pendidikan Kebudayaan : Jakarta. 